\section{Without Social Context?}

\author{
N. J. Enfield
}

W. Tecumseh Fitch's wide-ranging survey The Evolution of Language - features a cautionary tale against jumping to conclusions from the anatomy of dead animals. Comparative research on mammalian vocal tract anatomy had regarded the human "two-tube" arrangement (the result of a permanently descended larynx) as unique to our species. Much was known about the anatomical structure of the vocal tract in other mammals, but nobody had looked at it in action. When Fitch (a cognitive biologist at the University of Vienna) made x-ray video recordings of goats, dogs, and deer, he found that these animals dynamically create the twotube vocal cavity by temporarily descending the larynx, but only while actually vocalizing (1). This fact, which has consequences for the evaluation of competing theories of language evolution, cannot be observed when the ani$\mathrm{mal}$ is at rest (or, indeed, when dead or fossilized). The lesson is a general one: To build an adequate empirical basis for solving problems as difficult as the evolution of language, we must observe the target phenomena as directly as possible and in their proper contexts. It is therefore striking that in studying language, the dominant approaches to linguistics have pursued highly abstract analyses based on data that are only indirectly related to the phenomenon in its natural setting.

Linguists make a distinction between speech (the physical production of utterances) and language (the underlying grammar and meaning of those utterances). The great strength of Fitch's book lies in its treatment of speech. He provides a masterful ground-up survey of concepts and data in evolutionary biology that enable us to study the evolution of the vocal anatomy and its neural underpinnings. His treatment of language takes some dominant trends in linguistics to represent "over-arching areas of agreement," an interpretation that is understandable given that linguistics is not his home discipline.

The distinctly narrow conception of language foregrounded in The Evolution of Human Language is less justifiable, because its editors (Richard Larson, Viviane Déprez, and Hiroko Yamakido) are linguists. The chap-

The reviewer is at Language and Cognition Group, Max Planck Institute for Psycholinguistics, and Radboud University Nijmegen, Post Box 310, 6500 AH, Netherlands. E-mail: nick.enfield@mpi.nl ters in this volume vary in approach but are all loosely focused on a widely discussed 2002 review article by Marc Hauser, Noam Chomsky, and Fitch, "The faculty of language: What is it, who has it, and how did it evolve?" (2). Each of the three coauthors contributes his own chapter following up on that paper.

In their article (reprinted in Larson et al.), Hauser, Chomsky, and Fitch distinguished between faculty of language in narrow and broad senses. They defined the former as an "abstract linguistic computational system ... independent of the other systems with which it interacts and interfaces" and described the latter as made up of those other cognitive systems that are crucial for language but that may have broader functions. In his singleauthored chapter in Larson et al., Chomsky maintains the centrality for language evolu- defend against certain (mis)readings of his own views, while Fitch moves the debate forward by usefully distinguishing among meanings of "recursion," a concept prominent in the 2002 review and a topic of subsequent controversy. Chomsky takes his chapter as an opportunity to boldly assert his personal position on language evolution. Many linguists will feel a familiar sense of frustration at his omission or dismissal of decades of prominent and successful linguistic research that has not necessarily aligned with various influential Chomskyan programs. The problem is that nonspecialist readers will not learn from these chapters about the profound methodological and theoretical upheaval that is currently under way in linguistics thanks to the recent work of many prominent scientists of language [e.g., (4-6)]. Empirical and theoretical offerings from psychology, linguistics, and anthropology are supplying cognitive science with new approaches to language - in particular, new ways to understand the role of general cognitive capacities in making language what it is.

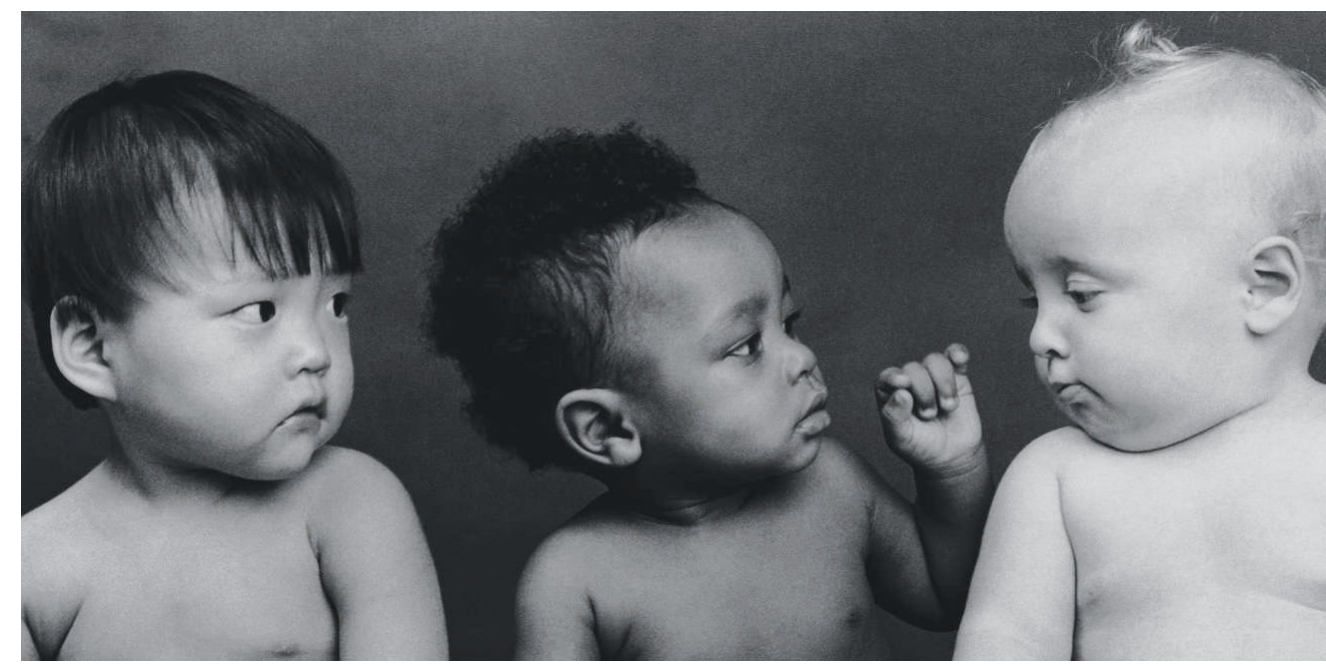

Communication without syntax.

tion of an abstract and narrow language faculty, driving a saltationist argument whose central hypothesis is that "some genetic event rewired the brain." Both Fitch (in his book) and Hauser (in his chapter) now explicitly acknowledge the possibility that the putative narrow language faculty "may be completely empty" (i.e., may not exist), and this is indeed what many researchers in the cognitive sciences currently believe. There are welldeveloped gradualist evolutionary arguments that language is entirely grounded in a constellation of cognitive capacities that each - taken separately — has other functions as well (3).

Hauser uses his chapter as a chance to
The previous focus on an abstract and narrow language faculty in linguistics has been driven by forms of research that are surprisingly far from the empirical, data-driven approach that Fitch insists is needed. The research technique long favored in generative linguistics has been to employ "grammaticality judgment" data to infer the underlying syntactic structure of sentences and, through this, to generate hypotheses about linguistic cognition. The linguist constructs imagined target sentences, checking to see if they are considered acceptable to native speakers. But such data notoriously give rise to irresolvable disagreements about whether an example sentence is in fact permissible (7-9). Not only 
are such measures unreliable, they are indirect (being metalinguistic rather than linguistic) and devoid of proper context. The conclusion to be drawn from this is analogous to that of Fitch's X-ray video studies: grammaticality judgments are the dead animals of linguistic science. Fortunately there are major lines of linguistic research that go beyond these static and circuitous methods, giving us direct access to language in its dynamic context. These approaches-hardly visible in either book-stand to be of central importance for future research on language evolution.

One such line of work meets Fitch's plea for datadriven research to a degree unprecedented in the history of linguistics. By exploiting newly available massive natural language corpora and pow-

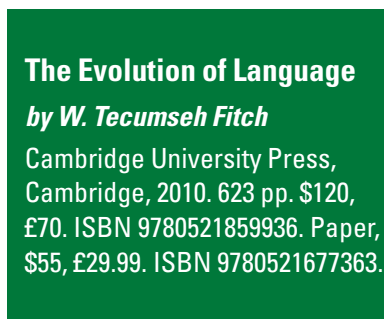

\section{The Evolution of}

Human Language

Biolinguistic Perspectives

Richard K. Larson, Viviane

Déprez, and Hiroko Yamakido,

Eds.

Cambridge University Press,

Cambridge, 2010. 279 pp. $\$ 105$,

£60. ISBN 9780521516457. Paper,

$\$ 41$, £23.99. ISBN 9780521736251. erful computing, scientists are beginning to capture the dynamics of language as a population phenomenon $(10,11)$. Large-scale statistical analysis of variation and frequency of actual output structures from members of a speech community not only captures population-level variation in the behavioral phenotype (crucial for understanding any evolutionary process), it also quantifies the variation in input that an infant will encounter when acquiring a first language.

The ethology of language as a system for communication provides a second approach essential for understanding language evolution. Some have argued for the critical importance of language's social functions to one simply needs to look at the data: normal human infants achieve rich communication without syntax when they are at the one-word stage of language acquisition (around age 12 to 18 months). Moreover, before this stage, infants can communicate without any language at all. How do they do it? By recourse to bodily forms of signaling (e.g., pointing gestures and gaze) riding on a chassis of elite human capacities for cooperation, prosociality, and naïve psychology — as stressed by Dan Sperber and Gloria Origgi in Larson et al. and touched on in the chapters by Derek Bickerton and Paul Bingham and in Fitch's book. We can communicate without syntax. What we can't do is communicate without a cognitive and bodily infrastructure for social interaction. But linguistics has little to say about this. The empirical domain of language in its role as a central tool for human social life remains untouched by the mainstream of linguistics and is now largely in the hands of sociologists, anthropologists, and psychologists.

As these two books show, everyone now agrees that it is possible and desirable to conduct research toward understanding the evolution of language. And everyone agrees that there is a very great deal of work to be done. An urgent prerequisite for this line of research-surprisingly not yet on the common agenda - is a comparative understanding of language (and related communicative systems) in the dynamic context of human social behavior.

\section{References}

1. W. T. Fitch, D. Reby, Proc. Biol. Sci. 268, 1669 (2001).

2. M. D. Hauser, N. Chomsky, W. T. Fitch, Science 298, 1569 (2002).

3. J. R. Hurford, The Origins of Meaning: Language in the Light of Evolution (Oxford Univ. Press, Oxford, 2007).

4. M. Tomasello, Origins of Human Communication (MIT Press, Cambridge, MA, 2008).

5. W. Croft, Radical Construction Theory: Syntactic Theory in Typological Perspective (Oxford Univ. Press, Oxford, 2001).

6. N. Evans, S. C. Levinson, Behav. Brain Sci. 32, 429, discussion 448 (2009)

7. C. T. Schütze, The Empirical Base of Linguistics: Grammaticality Judgments and Linguistics Methodology (Univ. Chicago Press, Chicago, 1996).

8. E. Dabrowska, Linguist. Rev. 27, 1 (2010).

9. E. Gibson, E. Fedorenko, Trends Cogn. Sci. 14, 233, discussion 234 (2010).

10. C. D. Manning, H. Schütze, Foundations of Statistical Natural Language Processing (MIT Press, Cambridge, MA, 1999).

11. R. Bod, J. Hay, S. Jannedy, Eds., Probabilistic Linguistics (MIT Press, Cambridge, MA, 2003).

12. R. I. M. Dunbar, Behav. Brain Sci. 16, 681 (1993).

10.1126/science.1194229

\section{Wrong Turns from Worst Worries}

\section{Thomas May}

$\mathrm{G}$

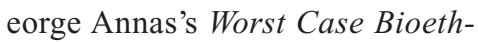
ics: Death, Disaster, and Public Health offers a valuable addition to the public policy literature. Its principal theme, how a fear of death can distort policy, should be considered by policy-makers at all levels. As readers familiar with his work might expect from the Boston University bioethicist, the book overall has a

The reviewer is at the Center for the Study of Bioethics, Medical College of Wisconsin, 8701 Watertown Plank Road, Milwaukee, WI 53226, USA. E-mail: tmay@mcw.edu pronounced focus on human rights, which is reflected in each of its three sections.

In the first section, "Death and Disaster," Annas argues that fear of death is at the core of the challenges facing the U.S. healthcare system and that meaningful reform requires that we, as a society, confront this fear. To illustrate how such fear frames our approach, he begins with chapters examining the problems facing healthcare reform and the threats posed by
Worst Case Bioethics

Death, Disaster, and Public Health

by George J. Annas

Oxford University Press,

New York, 2010. 359 pp.

$\$ 39.95, £ 27.50$.

ISBN 9780195391732 bioterrorism and medical emergencies. From this basis, Annas turns to discuss how responses to our fear of death have resulted in problematic policies that threaten basic human rights; he includes individual chapters on torture and war.

The second section, "Death and the Constitution," focuses on medical decision-making concerning issues involving death in the context of constitutional judicial decisions (primarily at the level of the U.S. Supreme Court). Annas's purpose is both to provide context and to illustrate how extreme (worst case) scenarios in general, and fear of death in particular, 